\title{
DIAMANTES Y HERRUMBRE: LEOPOLDO ZEA Y EL ESPÍRITU DE COMUNIDAD
}

\author{
DIAMONDS AND RUST: LEOPOLDO ZEA AND THE COMMUNITY SPIRIT
}

Andrés Kozel ${ }^{(*)}$

Consejo Nacional de Investigaciones Científicas y Técnicas, Ciudad de Buenos Aires

Resumen: El artículo busca avanzar en el esclarecimiento de los dos horizontes problemáticos siguientes: 1) las inquietudes que llevaron al pensador mexicano Leopoldo Zea (1912-2004) a ubicar la idea-imagen del espíritu de comunidad en el corazón de su propuesta filosófica y, 2) el collage de referencias sobre el cual se apoyó dicho centramiento. "Comunidad" es una noción significativa tanto para las ciencias sociales como para múltiples modalidades de cultivo de la tradición latinoamericanista.

Palabras clave: Comunidad; Desarrollo; Leopoldo Zea.

Abstract: The article seeks to clarify two problematic horizons: 1) the concerns that led the Mexican philosopher Leopoldo Zea (1912-2004) consider the idea-image of the community spirit in the core of his philosophical proposal and, 2) the collage of references in which that addressing was based. "Community" is a significant notion for the social sciences and for multiple areas of study within the Latin Americanist tradition.

Key words: Community; Development; Leopoldo Zea.

(*) Doctor, Profesor de la Universidad Nacional de San MArtin; investigador de lo Consejo Nacional de Invetigaciones Científicas y Técnicas. E-mail: <andres.kozel@gmail.com>. Recibido en: 22.02.2015, aceptado en: 12.06.2015. 


\section{INTRODUCCIÓN}

Leopoldo Zea fue un destacado pensador mexicano que vivió entre 1912 y 2004. Mi hipótesis para leer su obra indica que en su itinerario cabe identificar un lustro capital, el que va de 1952 a 1957. En sus escritos de ese lapso, Zea postuló un marcado contraste entre las experiencias históricas mexicana e iberoamericana de un lado y la anglosajona del otro, procurando poner de relieve los rasgos valorables de la primera. Sostengo que recién a partir de entonces cabe hablar con propiedad de un Zea con voz asertiva y característica, de una ecuación Zea en sentido pleno. Antes de 1952, hubo una etapa germinal, en la cual quedaron perfilados un programa de trabajo y unas preguntas a las que los escritos del lustro referido procuraron responder. Después de 1957, se registraron variaciones de interés diverso, atadas, por una parte, a la formulación perfilada en el momento clave y, por otra, a las coyunturas políticas y culturales en las que se fueron inscribiendo las intervenciones.

Durante el lustro capital, las búsquedas de Zea lo condujeron a recuperar las nociones de incorporación, mestizaje y espíritu de comunidad, a las que presentó como cualidades específicas y apreciables del orbe iberoamericano. De esas nociones, la más relevante, en virtud de su densidad y alcance, es la de espíritu de comunidad. El argumento de América en la historia, libro-hito que coronó la etapa, se vertebra en torno a esa idea-imagen: el espíritu de comunidad es presentado como el rasgo que singulariza, valorizándola, la entera experiencia histórica iberoamericana (ZEA, 1957; KOZEL, 2012, cap. 3).

En este artículo quisiera continuar avanzando en el esclarecimiento de los tres horizontes problemáticos siguientes: 1) las inquietudes que llevaron a Zea a ubicar la idea-imagen referida en el corazón de su propuesta; 2) el collage de referencias textuales y extra-textuales sobre el cual se apoyó dicho centramiento; 3 ) las posibilidades y límites de una relectura actual de la clásica formulación. En relación con esto último, quisiera adelantar que considero no sólo pertinente sino además estimulante tentar una reapropiación de la propuesta zeiana. Decir la comunidad supone participar, desde un ángulo específico, de varios debates: el que alude al vínculo entre creencias religiosas y prácticas económicas; el que explora las relaciones entre capitalismo y moral (BOLTANSKI y CHIAPELLO, 2010, p. 43); el que piensa la relación entre la cultura latinoamericana y la modernidad (MORSE, 1982; ECHEVERRÍA, 2000); el que aborda la temática del desarrollo y sus pliegues (SVAMPA y VIALE, 2014, p. 374). Por eso, explorar las texturas y las modulaciones de la comunidad interesa desde el punto de vista de enriquecer una ciencia social abierta a tematizar su fecundidad heurística (BAUMAN, 2003; DE MARINIS, 2010; 2012); interesa, también, en relación con cultivar la tradición latinoamericanista, por definición sensible a lo que una noción como ésa contiene de tensión crítica ante la experiencia dominante de modernidad.

\section{UN LENGUAJE PARA DECIR LA CRISIS DEL MUNDO}

La primera etapa de la producción intelectual de Zea comprende la década larga que va de 1939 a 1951. Dicha etapa puede a su vez subdividirse en dos sub-periodos, 
el propiamente inicial, y el que cabría llamar de consolidación, separados por el viaje del joven autor por varios países americanos. En más de una oportunidad, Zea narró cómo fue su maestro José Gaos quien, hacia 1939, lo instó a dedicarse con exclusividad a la filosofía y, enseguida, a consagrarse al estudio de un tema mexicano (ese tema sería, como es sabido, el positivismo). También precisó que fue por seguir indicaciones del mismo Gaos que acabó consagrándose al estudio de la historia de las ideas latinoamericanas primero y a elaborar una filosofía de la historia (latino) (ibero)americana después (ZEA, 2004). La "Carta abierta" gaosiana de 1949-1950 jugó un papel crucial en este último sentido (GAOS, 1950), y puede ser considerada el hito que marca el inicio de la transición entre la primera etapa de la producción zeiana y el lustro capital que nos interesa estudiar.

En la primera etapa del itinerario zeiano corresponde destacar dos impulsos seminales, ambos heredados de la prédica gaosiana: de un lado, el fervor de lo propio; del otro, la promesa de una metafísica. Recién arribado a México, Gaos planteó una conexión entre la entidad histórico-cultural Hispanoamérica y cierta constelación de valores apreciables, de cuyo recentramiento esperaba algo en relación con la superación de la crisis del mundo. En aquel Gaos, la apreciabilidad de los valores asociados a los pueblos hispánicos aparecía ligada a lo que en ellos había de histórica vocación a la trascendencia, y de concomitante distancia crítica ante el inmanentismo irreligioso contemporáneo. De acuerdo con su diagnosis, el predominio del inmanentismo irreligioso subyacía a la conmoción de los principios que había dado paso a la guerra y su locura. Habiendo sido causa la frustránea deriva en la modernidad de los pueblos hispánicos, la vocación trascendente y la distancia con respecto al inmanentismo encerraban, a los ojos de Gaos, claves aptas para abrirse paso hacia la composición de una "metafísica de nuestra vida", con base en la cual pudiera instaurarse una renovada comunión de fe trascendente en un mundo ya-sin-Dios (GAOS, 1993, 1990, 1992; KOZEL, 2012).

Tanto para el recién llegado Gaos como para el joven Zea, lo que el mundo ibera y América podían aportar a la solución de la crisis del mundo quedaba enlazado a un replanteamiento de tipo metafísico, y esto no en un sentido tradicional, sino en el de llamar la atención sobre la necesidad de perfilar/recrear una constelación de valores que permitiera, sea instaurar una renovada comunión de fe trascendente (GAOS), sea dotar de sentido a unas prácticas a la deriva (ZEA). Es evidente que estas formulaciones descansaban sobre una apropiación de algunas zonas de la obra de José Ortega y Gasset; el punto merecería consideraciones adicionales; no hay espacio para delinearlas aquí. Lo que interesa destacar es que, en el caso del joven Zea, y más allá del innegable fervor, no resulta sencillo precisar en qué consistía lo propio hispanoamericano, es decir, de qué estaba hecho eso hispanoamericano que podía apreciarse. Examinar esto con atención es indispensable para calibrar el peso de las novedades introducidas durante el lustro capital.

Desde el punto de vista que aquí interesa, el texto más importante del joven Zea es En torno a una filosofía americana, libro que reúne una serie de conferencias impartidas a principios de 1942 (ZEA, 1945). El argumento y los enredos silogísticos que contiene se dejan reproducir así: América no tuvo historia porque no la necesitó (vivir de la imitación le bastó para solucionar sus problemas), o América sí tuvo una historia que 
no sabemos ver porque la miramos mal (la dolencia estaría en la mirada, no tanto en la entidad o su historia; o, más rebuscada pero tal vez más profundamente, la dolencia residiría precisamente en el hecho de que la entidad no consigue mirarse bien a sí misma). En cualquier caso, esa historia nos mostraría que sí hay algo propio, que sólo se hace expreso de un modo negativo, como ausencia, miopía o ceguera (pero si buscamos en nosotros mismos no encontramos eso que queremos llamar nuestro). Lo "propio" parece ser el sentimiento de bastardía, de inadaptación, de inferioridad; en el mejor de los casos, una suerte de anhelo pobremente determinado. Sería en los límites, en el no poder ser plenamente otro pese a habérselo propuesto, donde residiría la americanidad. Lo propio sería la inefable causa por la que sólo se han producido malas copias de la cultura europea; esa inefable causa sería lo americano que resiste, que no quiere ser lo que no es aunque no sepa lo que es. El problema planteado era importante; la tentativa de resolución, poco satisfactoria. En efecto, no es simple articular el fervor por inefabilidades como ésas - resistentes, pero denotativas de irredimibles incapacidades - con la promesa de contribuir a la superación de la crisis del mundo. Si los desarrollos del joven Zea comulgaban con los de su maestro en su orientación general (de la crisis se saldría por la vía de algún tipo de reformulación metafísica), no poseían, todavía, análogo espesor histórico-filosófico. Intelectualmente más maduro entonces, Gaos estaba en condiciones de ofrecer respuestas más elaboradas. Por razones múltiples y complejas que acaso quepa lamentar, el fervor hispanoamericanista gaosiano se diluiría con los años.

Causa inefable de la mala copia, límite y conjunto vacío, lo propio no era en el primer Zea una esfera que se dejase apresar con precisión. Tanto las razones del fervor como los posibles contenidos de la metafísica permanecían en una nube de inefabilidades. Con el paso de los años, y gracias al procesamiento de un extenso y variado repertorio de elementos, Zea labró formulaciones más satisfactorias. Logró hacer, en cierto modo, que lo inefable hablara. Lo hizo en sucesivas tentativas desparejas, de las cuales se desprendieron definiciones más bien ostensivas, que no siempre se dejan sumar entre sí. Más semejante a un collage abigarrado que a un constructo intelectual sistemático, la ecuación resultante alcanzó, en su inestabilidad y en sus tensiones, una innegable riqueza simbólica y una enorme significación cultural. Como adelanté, la operación quedó cimentada en la recuperación de, y en la insistencia sobre, la idea-imagen del espíritu de comunidad. Veamos de qué manera sucedió.

\section{ANTECEDENCIAS DEL COLLAGE: DE GAOS A TOYNBEE, PASANDO POR BILBAO}

Del viaje americano de mediados de la década del cuarenta Zea se trajo dos gemas preciosas, ideas-imágenes tomadas de Andrés Bello y de Francisco Bilbao, con cuyas obras tomó contacto entonces por primera vez. Esa asimilación lo dejó bien posicionado para comenzar a dotar de componentes menos difusos a su fervor de lo propio. Hasta donde sé, el mecanismo se puso de manifiesto por vez primera en un artículo elaborado en ocasión del centenario de la guerra de 1847-1848 (ZEA, 1948). La última sección de ese artículo se titula, justamente, Lo positivo en Hispanoamérica (positivo, en el sentido de apreciable). Al joven Zea le impresionó la afirmación de Bello según la cual, si todo 
hubiese sido tan negativo en lo español y en sus colonias, no podría explicarse la grandeza de los hombres que llevaron a cabo la gesta de la independencia. Le impresionó también, más vivamente aún, el impulso diferenciador entre las dos Américas hallado en Bilbao. Tempranamente, y a diferencia de las valoraciones decimonónicas más usuales, Bilbao había planteado una inversión de los signos del contraste: si los del Norte exterminaban a los nativos, en el Sur predominaban la incorporación y mestizaje; si los del Norte caían en la tentación de los titanes, los del Sur respetaban la dignidad humana; si los del Norte encontraban en el goce de las cosas terrenales el fin último de la existencia, los del Sur ubicaban a éste en un plano que no es el terrenal, y que se ligaba con algún tipo de consideración trascendente. No sin sagacidad, Zea conectó las contraposiciones bilbaínas con los desarrollos de Rodó y Vasconcelos. A partir de ese momento, esa articulación pasó a formar parte de su acervo de referencias predilectas. No es excesivo postular que la semilla de sus respuestas al tema de lo propio positivo durante el lustro capital se encuentra en esos hallazgos. Llama la atención que, desde el punto de vista de la madurez de la ecuación, la última sección del artículo de 1948 parece ser "posterior" al libro Dos etapas del pensamiento en Hispanoamérica, de 1949: poco hay en ese libro de recuperación con signo favorable de aspectos del pasado colonial o español. En cierto modo, pareciera que el artículo de 1948 es una derivación/profundización de los planteamientos vertidos en el libro aparecido en 1949; hay más de asertivo y distintivo en aquél que en éste (ZEA, 1949).

En su "Carta abierta", publicada a principios de 1950, Gaos instó a Zea a llevar a plenitud las interpretaciones filosóficas-históricas despuntadas en la Introducción del libro Dos etapas del pensamiento en Hispanoamérica. Tras glosarlo elogiosamente, Gaos invitó al ya maduro discípulo a emprender una vasta tarea de clarificación filosófica. El meollo de la recomendación era el siguiente: en vez de deshacerse del pasado, era preciso asimilarlo para superarlo; en vez de rehacerse según un presente extraño, era menester rehacerse según el pasado y el presente más propios con vistas al más propio futuro (GAOS, 1950). Pasado, presente y futuro más propios...: el consejo incitó a Zea a continuar explorando la inasible e inestable esfera de lo propio y a consagrarse a la elaboración de una filosofía de la historia (latino)(ibero)americana. Acometió el desafío a su manera, procediendo por acumulación y superposición asistemática de materiales y motivos, y dando forma a sucesivas tentativas resolutorias, que acuden a fórmulas que no son a-problemáticamente sumables. Además, y aun cuando no abandonó del todo el horizonte semántico de los años cuarenta, sus soluciones se recostaron sobre una constelación de referencias distintas a las cultivadas por su maestro.

En Conciencia y posibilidad del mexicano, ensayo publicado originalmente en 1952 como segundo volumen de la colección "México y lo mexicano", Zea escribió que la zozobra, la inseguridad y la inconsistencia eran rasgos característicos de la experiencia histórica mexicana. Planteó que esos rasgos, evidentemente inmanentistas, podían servir de ejemplo a un mundo en crisis, que necesitaba de soluciones inmanentistas para encarar sus problemas. La imagen del ejemplo y su aura conectan con la promesa de 1942:

Viviendo a pesar de todo; viviendo al día, pero viviendo siempre, el mexicano puede ya ofrecer a un mundo, a ese mundo que nuevamente se siente inseguro y zozobrante, una 
gran experiencia. Esto es, una experiencia que puede ser ejemplar, que puede servir de ejemplo a otros pueblos. Una experiencia cuya conciencia puede, quizá, dar la solución de muchos de los problemas en que se debate la humanidad actual. Experiencia para un mundo que parece haber gastado su patrimonio de soluciones trascendentales, y que se ve obligado a vivir dentro de soluciones de carácter inmanente, limitadas; soluciones que habrán de ser continua y permanentemente renovadas. Esto es, ejemplo o experiencia para un mundo que tiene que vivir como el nuestro, al día. Pero un día cuya inseguridad sea el mejor índice del desinterés que hace posible la verdadera creación, ese afán inútil, pero creador de ser más que un hombre (ZEA, 2001, p. 62-63).

Es importante subrayar la oración que comienza "Experiencia para un mundo que (...)", claramente tributaria de las formulaciones gaosianas sobre la conexión entre inmanentismo y crisis. Hay en este ensayo otro elemento clave. Lo propio positivo que Zea estaba procurando caracterizar aparece ligado a la noción de comunidad, incipientemente contrapuesta, no, todavía, a la noción de sociedad, sino al "maquinismo que caracteriza a las sociedades occidentales contemporáneas (...)”:

Esta sociedad nuestra, pese a todos los defectos, a todas esas fallas que tan conscientes nos son, puede dar origen a un tipo de comunidad verdaderamente humano, sin caer, ni en el maquinismo que caracteriza a las sociedades occidentales contemporáneas, ni en la anarquía, inseguridad plena e irresponsabilidad en que estamos siempre propensos a caer ineludiblemente. Comunidad que ligue a los hombres con los hombres y no con entidades abstractas, incontrolables y deshumanizadas. Comunidad en la cual los individuos a fuerza de saberse personales y únicos, se sepan también los únicos y personales responsables de su acción. Sociedad en la que termina ese fácil abandonarse a la voluntad de un caudillo, y se dé lugar a un alto sentido de responsabilidad personal, tanto por lo que se refiere a los gobernantes como a los gobernados; un sentido de responsabilidad que abarque a toda clase de funciones (ZEA, 2001, p. 67).

No fue antes de 1952 ni después de 1953 que Zea tomó contacto con la obra de Arnold Toynbee. De esa asimilación hay huellas profundas en sus escritos, tanto inmediatos como ulteriores. La presencia del ideario toynbeeano se dejó sentir, nítidamente, en El occidente y la conciencia de México, nuevo ensayo de tema mexicano publicado en 1953 como decimocuarta entrega de la colección "México y lo mexicano" (ZEA, 2001). La asimilación de Toynbee condujo a Zea a reconfigurar enteramente su interpretación de la historia. No es excesivo afirmar que, a partir de entonces, Zea se consagró a corregir a Hegel desde Toynbee. Sin asimilación de Toynbee - asimilación que fue, a su vez, "mala copia" - no habría habido ecuación Zea, no plena, no como la conocemos. El alcance de esta conjetura de alguna manera contra-fáctica puede calibrarse cotejando los dos libros que Zea dio a conocer en los años cincuenta: el pre-toynbeeano América como conciencia y el libro-hito América en la historia, que es el más toynbeeano de todos sus libros (ZEA, 1953 y 1957, respectivamente). "Mala copia": se detecta un foco problemático de peso en el modo en que Toynbee consideraba la tensión entre la occidentalización y la vigencia de las identidades particulares. Más allá de algunas oscilaciones que valdría la pena clarificar, en Toynbee la occidentalización parece ser un horizonte tan inevitable como inevitablemente homogeneizador. Homologada al caballo de Troya, la técnica occiden- 
tal es vista como algo que va emponzoñando a las culturas a las que roza, afectándolas estructural y decisivamente (TOYNBEE, 1953). Aunque le resultaba incómoda, Zea no polemizó abiertamente con esa afirmación, sino que acudió, una vez más sagazmente, a una sentencia del propio sabio británico, según la cual la contienda a ese respecto estaba todavía abierta.

No hay que olvidar que Toynbee visitó México en 1953, ocasión en la que impartió una serie de conferencias, luego publicadas, también, en la colección "México y lo mexicano" (TOYNBEE, 1955). El (re)encuentro con Hegel y el encuentro con Toynbee que lo enmarcó constituyen dos rasgos que especifican grandemente las búsquedas de Zea en relación con las de Gaos: el maestro transterrado permaneció impermeable a ambos influjos (también a otros, como el de Sartre).

El Occidente y la conciencia de México (1953) luce en su frontispicio una expresiva dedicatoria a Toynbee. En el corazón del volumen se detecta una clara toma de posición sobre qué es y qué puede ser el historicismo. En un parágrafo fundamental, Zea discute discreta pero firmemente con Edmundo O'Gorman sobre el tema. En concreto, Zea no estaba de acuerdo con la idea de O'Gorman según la cual el historicismo debía ser pensado como un neo-aristocratismo ${ }^{(1)}$. Para Zea, adherir al historicismo no tenía por qué llevar a pensar que hubiese hombres de los que cupiera decir que fueran más o menos plenamente hombres que otros. Inspirándose explícitamente en Toynbee, Zea introduce la noción de regateo de humanidad como categoría principal para pensar el asunto. En esta línea, se resiste a conceder que quienes ocupan los lugares de predominio sean más humanos que el resto; a sus ojos, lo que sucede es otra cosa: los privilegiados les regatean a los otros su humanidad. En Zea, el historicismo no es aristocratismo, sino que es, por el contrario, toma de conciencia de la relatividad histórica de todas las culturas y de su, en principio, igual o análoga valía. Toma de conciencia, en suma, de que el regateo es algo que debe ser denunciado, desmontado y superado.

\section{EL COLLAGE FASCINANTE: HACIA TÖNNIES Y EL ERASMISMO HISPANO, VÍA GUATEMALA}

Entre 1948 - momento en que Zea había textualizado su asimilación del contraste bilbaíno - y 1953, el motivo relativo al contraste entre las dos Américas quedó como suspendido. El "guatemalazo" de 1954 fue el catalizador contextual que condujo a Zea a movilizar, en una dirección específica, los materiales acumulados hasta entonces. El resultado fue una reformulación más intensa del contraste. Los efectos inmediatos de la caída de Árbenz pueden apreciarse en su artículo “¿Bondad norteamericana e ingratitud mundial?" (ZEA, 1955). Lejos de su juvenil inter-americanismo, las energías de Zea se reorientaron en un doble cauce: poner en cuestión la política exterior estadounidense y caracterizar mejor el ámbito de lo propio (re)apreciado de esta América. A la salida del proceso, que cabe situar en 1957 , lo propio positivo había adquirido un espesor conside-

(1) O'Gorman había planteado esta idea en su extenso ensayo titulado Sobre la Naturaleza Bestial del Indio Americano (O'GORMAN, 1941). La consideración del entramado polémico entre Zea y O'Gorman es clave para entender el desarrollo de las ecuaciones de ambos a partir de los años cincuenta. 
rable, ausente en los trabajos previos, y acaso inigualado en los ulteriores. El examen de "¿Bondad norteamericana...?" permite apreciar sobre todo la navegación del primero de los cauces. Zea erosiona críticamente las ideas de "destino manifiesto", "predestinación" y otras conexas. En clave toynbeeana, insta a los Estados Unidos a emprender una suerte de acto de contrición, condición necesaria para la salvación de toda la cultura occidental. Por su parte, la revisión de América en la historia permite abundar en los mismos motivos y adentrarse también en el segundo cauce, ligado al ensanchamiento y densificación del ámbito de lo propio positivo, enriquecido a partir del centramiento de la idea-imagen de espíritu de comunidad. En pocas palabras, a partir de la asimilación del impacto del guatemalazo - conceptuado como derrota moral de los Estados Unidos -, Zea se consagró a reelaborar el contraste bilbaíno desde lo que había aprendido de Toynbee y tomando la idea-imagen aludida como clave de bóveda de su construcción ${ }^{(2)}$.

Antes de decir más algo sobre el libro-hito de 1957, vale la pena detenerse en una olvidada pero importante estación textual intermedia: "Formas de convivencia en América", contribución cuya datación precisa presentó en principio algún inconveniente, pero que indudablemente debe situarse en 1956, esto es, entre la caída del presidente Árbenz y la publicación de América en la historia. Se trata de un nuevo intento de resolución a las inquietudes de 1942, que prolonga la línea de las tentativas de 1948 y de 1952-1953, aunque con algunas novedades de peso. La principal de esas novedades es la apropiación explícita de los conceptos tönniesianos de comunidad y sociedad, creativamente puestos en relación con las nociones de barbarie y civilización. Esquemáticamente: si la América ibera puede valorarse positivamente por ser comunidad y negativamente por ser barbarie, la América sajona puede valorarse negativamente por ser sociedad y positivamente por ser civilización. Vale la pena escuchar la voz de Zea:

Las formas de convivencia de cada una de estas Américas, enraizadas en dos expresiones de la Cultura Occidental, podrían ser encuadradas dentro de la doble clasificación que sobre las formas de convivencia ha establecido el sociólogo alemán Ferdinand Tönnies: Comunidad y Sociedad. Clasificación muy general, pero que en muchos aspectos podría corresponder a lo que se ha establecido en la llamada América ibera y la sajona. Formas de convivencia que en la cultura Occidental se ha(n) expresado en el paso de la cristiandad a la modernidad. En este paso el racionalismo - máxima expresión de la modernidad - desliga la relación causal medio-fin de la convivencia, haciendo de la convivencia un medio, más o menos adecuado a los fines que cada individuo persigue en particular. El racionalismo subordina las entidades colectivas, las formas de convivencia basadas en un conjunto de intereses que trascienden a los individuales, a otra forma de convivencia que descansa en los intereses concretos de los individuos. En la comunidad los individuos se enlazan, conviven, en función con un fin que los trasciende (...) (ZEA, 1971, p. 54).

Para Zea, esta actitud diversa ante la vida se expresó en las relaciones que iberos y sajones sostuvieron con los naturales de América: si los primeros buscaron integrarlos,

(2) En América en la historia (1957), Zea glosa la "Fábula" del ex presidente guatemalteco Arévalo (ARÉVALO, 1956). El golpe de Guatemala, llevado a cabo con el apoyo del gobierno estadounidense, dejó en Zea marcas más sensibles que el otro acontecimiento crucial del año, el suicidio de Getúlio Vargas. 
subordinación mediante, al imperio de la cristiandad que querían construir, los segundos los convirtieron en instrumentos de sus afanes de aprovechamiento individual o directamente los eliminaron. La divergencia se expresó también, de acuerdo con Zea, en las relaciones que iberos y sajones establecieron entre sí: cada América vio en la otra su propia negación. Mientras los americanos sajones se afianzaron como expresión máxima del Mundo Moderno, los iberoamericanos constataron su incapacidad para desenvolverse en dicho mundo, llegando a autoconcebirse como pueblos al margen de la civilización, como expresión del primitivismo y de lo que Sarmiento llamó barbarie. En efecto, sostiene Zea que, a lo largo del tiempo, una América buscó expandir sobre la otra esa civilización, extensión de los intereses concretos de los individuos que la forman, en tanto que la otra trató de contener dicha expansión, tratando de fortalecerse por la vía de la asimilación de la cultura que, en su opinión, venía originando la grandeza de la América triunfante. Si las formas de convivencia apoyadas en la razón y orientadas a su aprovechamiento por los individuos recibieron el nombre de civilización, las de índole más gregaria, recostadas sobre lazos sanguíneos, de amistad o carismáticos, recibieron el nombre de barbarie. Sin embargo - continúa, con pulso firme, Zea -, la referida dualidad generó consecuencias imprevistas, no exentas de paradojas ni ambigüedades. Mientras que en no pocas ocasiones los iberoamericanos civilizadores emplearon métodos violentos y bárbaros para intentar hacer avanzar a sus sociedades en la dirección que deseaban, los americanos sajones, individualistas y en extremo preocupados por su propia seguridad, fueron dando lugar a sociedades que acabaron por constreñir la libertad de sus miembros. La ecuación Zea vibra plena cuando afirma que en esas sociedades que buscan preverlo todo, la espontaneidad se reduce a la mínima expresión, y el individuo debe desenvolverse dentro de cuadros de acción cada vez más estrechos. Así, el individuo se va transformando en una especie de autómata. En ambientes como ésos, cada día tienen menos sentido lo imprevisto, lo improvisado, el gasto inútil y gratuito, todas instancias que son fuentes de actividad creadora. Lo anónimo y lo abstracto triunfan sobre lo concreto, a tal punto que la pregunta "iseguridad para quién?" puede llegar no sólo a plantearse, sino a quedar sin respuesta.

En contraposición a ese mundo, que es el prevaleciente en la época moderna, está el que forman comunidades que conservan rasgos primitivos, como es el caso de Iberoamérica. Es éste, para Zea, un mundo más inseguro, lleno de zozobras, en el que las relaciones de convivencia descansan sobre el parentesco o la amistad, un mundo que no es tanto una sociedad de ciudadanos, ligados entre sí por vínculos formales, como una comunidad de parientes o amigos, enlazados por relaciones directas y concretas. En un mundo así, las leyes apenas alcanzan a encubrir situaciones de hecho, originadas por voluntades concretas, y la burocracia tiende a ser eludida por esa otra institución tan característica que es la "coima" o la "mordida", la cual permite el "ajuste concreto" de las relaciones entre individuo y sociedad. En estos ámbitos - prosigue Zea -, importa mucho ser amigo del Presidente de la república, de sus ministros o de cualquiera de sus funcionarios; amigo de sus amigos, o amigo de los amigos de sus amigos, en una cadena en la que siempre prevalece la relación personal. La ecuación Zea vuelve a vibrar plena cuando señala que esta modalidad de convivencia, más asociada a la noción de comunidad que a la de sociedad, es, a la vez que fuente de muchos de los males que aquejan a los pueblos 
iberoamericanos, posible punto de partida para un tipo de convivencia más humano que aquel en que han ido cayendo las sociedades modernas, de las cuales la América otra es el emblema. Esto es así porque entidades como Iberoamérica son comunidades capaces de ligar a los hombres con los hombres y no con entidades abstractas. Acudiendo al acervo de referencias que ya conocemos - Andrés Bello y, sobre todo, Francisco Bilbao -, Zea pone de relieve que, a pesar de sus defectos y de los frutos amargos a que ha dado origen, este tipo de convivencia es el que ha hecho posible relaciones de humanidad más justas. De la mano de Bilbao, Zea recupera, justo aquí, la luminosa imagen de la incorporación, el promisorio horizonte del centrar la vida en un plano no utilitario. Reescribe entonces, una vez más, pero ahora integrando sus palabras en un dispositivo de interpretación más robusto, que no todo fue negativo en el espíritu que anidaba en las comunidades iberas, sino que hubo, y eventualmente hay, en ellas algo, mucho, que les permitió triunfar sobre sí mismas. Escribe, también, que ese algo es un rasgo distintivo, no poseído por aquellos otros pueblos-modelo.

Múltiples elementos de interés hay en estos desarrollos de Zea. Ante todo, marcas que son reveladoras de específicos procesos de condensación, articulación y potenciación de casi todo lo que venimos estudiando. También, la certidumbre de que es preciso introducir al menos dos deslindes. Uno, con respecto a O'Gorman. Si es cierto que Zea había tomado distancia de la concepción o'gormaniana del historicismo, también lo es que ha hecho plenamente suyos los términos de la contraposición o'gormaniana entre las dos Américas (O'GORMAN, 1942). El otro, con respecto al equilibrio de los términos del cuarteto conceptual. De ninguna manera sería legítimo sostener que este Zea de 1956 ha optado por el par comunidad/barbarie en detrimento del par sociedad/civilización. Aun cuando no lo dice exactamente así, Zea parece querer retener todo lo que hay de positivo en la comunidad, aspirando a lograr paralelamente todo lo que hay de admirable en la civilización. Zea - el de 1956 y cualquier otro - está a una considerable distancia de rechazar en bloque la civilización moderna o de abogar por un retorno a la barbarie. Más complejamente, se revela entusiasta de la posibilidad de recuperar, preservar y promover incrustaciones Gemeinschaft en el seno de la sociedad moderna. Todavía más: anhela que el mundo todo cambie a partir de esa presencia Gemeinschaft. El mundo soñado por Zea es un mundo moderno humanizado, auténticamente universal y, por lo mismo, respetuoso de las particularidades. En esto, parece haber captado fielmente, y con sus tensiones características, aspectos medulares de la parenética implicada en la propuesta tönniesiana (SCHLUCHTER, 2011; ÁLVARO, 2010).

En cuanto a cómo fue que Zea tomó contacto con la obra de Tönnies, no es mucho lo que estoy en condiciones de decir. En primer lugar, la expresión comunidad apareció en sus textos con prescindencia de menciones expresas a Tönnies; es por tanto posible que Zea comenzase a emplear la expresión antes de tomar contacto con la obra del sociólogo alemán. En 1955 publicó un artículo sobre la presencia de las ideas alemanas en Hispano e Iberoamérica, en el cual hay una referencia a Tönnies, aunque meramente incidental (Zea, 1956, p. 83). Llama la atención que en su obra ulterior no volviera a emplear el cuarteto de conceptos y que no volviera a mencionar a Tönnies. Es difícil responder por qué Tönnies no tuvo un papel destacado en la arquitectura de América en la historia: ¿descuido?, ¿olvido?, ¿decisión deliberada de abandonarlo?, ¿decisión deliberada de tenerlo presente sin mencionarlo(...)? 
Como sea, lo cierto es que la idea-imagen del espíritu de comunidad es la que vertebra el libro de 1957, sobre el cual formularé cuatro comentarios que nos permitirán redondear la exploración. Primero: hay allí, acaso previsiblemente, una tematización de cuestiones asociadas con la historia del liberalismo y del orbe cultural anglo-sajón; en esto desempeñaron un papel importante las asimilaciones de Ernst Troeltsch, Harold Laski y Juan Antonio Ortega y Medina, entre otros. Segundo: hay allí, también, y más previsiblemente aún, un adentramiento en temáticas ligadas a la historia de España. Aquí resultó crucial la apropiación de la obra de Américo Castro, de la cual tanto José como Vicente Gaos (hermano menor de José) habían publicado sendas reseñas en revistas mexicanas (CASTRO, 1948; GAOS, J., 1949; GAOS, V., 1950). La apropiación de Castro tuvo lugar en paralelo con la de Erasmo y España, obra del sabio francés Marcel Bataillon (BATAILLON, 1950). Ambas fagocitaciones fueron en la línea de centrar argumentalmente, con signo preponderantemente positivo, la idea-imagen del espíritu de comunidad ibero. En esta perspectiva, la presencia de dicho espíritu es la razón última de la propensión a la incorporación y al mestizaje, distintiva de nuestro ámbito cultural. En Zea, el erasmismo hispano aparece como un momento importante de la genealogía de dicho espíritu, luego patente también en la "realeza iluminada", en el "despotismo ilustrado", en los "libertadores hispanoamericanos" y, también, en los "dictadores liberales". Encarnado por reyes, déspotas, señores de la guerra y dictadores, el espíritu de comunidad presenta en el libro de 1957 una coloración más "desde arriba".

Tercero: se verifica una marcada intensificación de la disposición zeiana a considerar los acontecimientos que estaban teniendo lugar en el resto del "mundo no occidental", verbigracia, para aquel momento específico, Bandung, Kenyatta, etc. Este Zea se revela altamente sensible a los avatares del proceso descolonizador entonces en curso. Paralelamente, se interesa grandemente por el orbe cultural ruso, llegando a postular una analogía entre eslavismo e iberoamericanismo. Vibra al glosar los escritos de Herzen y de Dostoievski. Vibra, en particular, al evocar la imagen dostoievskiana de la hermandad de todos los seres humanos, entendida como horizonte alternativo al individualismo deshumanizado predominante en la experiencia occidental. El mundo occidental humanizado de Zea, su mundo auténticamente universal, es, según parece, un mundo no plenamente occidentalizado, en el sentido de no completamente galvanizado. Da la impresión de que, caduco el regateo de humanidad, las particularidades no se disolverían, sino que accederían a una renovada vigencia.

Cuarto: pese a que, misteriosamente, Tönnies no es mencionado en esas páginas, y pese a que, en los escritos ulteriores Américo Castro y Marcel Bataillon también desaparecerían de sus referencias, la matriz interpretativa perfilada en América en la historia ya no sería abandonada. Es cierto que en los años siguientes se verificaron movimientos en la ecuación. En los tiempos de la Alianza para el Progreso, Zea volvió a interamericanizar - quizás con algún temor pero con algo más de fe que Rubén Darío - . Tras el asesinato de Kennedy y la escandalosa ocupación estadounidense en República Dominicana, irrumpió como un tercermundista radicalizado, próximo al lenguaje del último Che Guevara; a lo largo de esa etapa, en su recuperación de la comunidad el componente "desde arriba" fue sustituido por un mayor énfasis en el papel del "gentío materno". En los años noventa, emergió como un desarrollista ansioso, 
viendo en Clinton y en el TLCAN oportunidades doradas para México y América Latina. No hay tiempo aquí para dar razón de cada uno de esos desplazamientos. A riesgo de simplificar en demasía, cabe señalar que los mismos siguieron bastante de cerca las alternancias políticas estadounidenses y los vaivenes de la política exterior mexicana. Pero tampoco conviene llevar demasiado lejos esta última afirmación: Zea fue bastante más que un vocero de la cancillería de su país. Si es cierto que hubo cambios, también lo es que lo distintivo del pathos no se alteró. La noción de comunidad, y sobre todo, sus connotaciones (aunque no tanto la palabra espíritu, que desapareció), continuaron ocupando un lugar central en sus elaboraciones.

\section{COMUNIDAD, PALANCA ARQUIMÉDICA}

¿Qué podemos decir hoy acerca de las cuestiones implicadas en el espíritu de comunidad zeiano? Ante todo, reconocer el enraizamiento de la ecuación en un contexto histórico-social perfectamente determinado. Dicho reconocimiento debiera ser suficiente para prevenirnos contra la propensión a buscar en ella respuestas transparentes a nuestros interrogantes, que pertenecen a otro tiempo. Sin embargo, como enseña la mejor tradición hermenéutica, hay veces en que la toma de contacto con los textos clásicos nos permite acceder a verdades a las que difícilmente podríamos llegar de otro modo. Y no hay dudas de que Zea es un clásico del pensamiento latinoamericano y de la tradición latinoamericanista. Es cierto que sus formulaciones presentan irresoluciones, tensiones e inestabilidades, pero no menos cierto es que rasgos así se encuentran en muchos otros autores canónicos, sin que ello tenga como consecuencia necesaria volverlos menos interesantes o menos ricos. Antes bien, sucede lo contrario. Es mucho lo que puede aprenderse de la revisión atenta y relativamente empática de los desgarramientos y sinuosidades de quienes tentaron la aventura de pensar. De hecho, los estudios más recientes sobre las peripecias de la noción de comunidad en el seno de la teoría sociológica cuentan entre sus virtudes el mostrar que en los sociólogos clásicos una noción tan crucial como ésta ha sido, y todavía hoy es, trabajada en sentidos/registros distintos, en ocasiones de manera contradictoria y, por momentos, sin plena conciencia de ello. Comunidad es, a veces en una misma obra, antecedente histórico de la sociedad moderna, tipo ideal de relaciones sociales, escenario utópico, artefacto para la reconstitución de un lazo social desgarrado, término que menta el grado cero de la socialidad (...) (DE MARINIS, 2012). En Zea, que no es un clásico de la sociología, sino del pensamiento latinoamericano, la noción de comunidad también aparece trabajada en distintos registros y, a veces, contradictoriamente. Con el importante agregado de que, en su caso, por razones complejas - entre las cuales la opción deliberada por lo asistemático y la muy asumida concepción del trabajo intelectual como respuesta circunstancial, y hasta ideológica, a problemas circunstanciales -, la noción se desprende, como vimos, de un proceso de fagocitación, acumulación y superposición de materiales heteróclitos más que de un trabajo teórico realizado "en puridad". Es por ello que preferí hablar, desde el comienzo, de idea-imagen, y no de concepto, y ni siquiera de idea a secas. Estimo que es suficientemente clara la doble alusión contenida en la noción de idea-imagen: una idea-imagen insinúa más de lo que efectivamente define y, en su calidad de amuleto o 
comodín, consigue tanto resolver cuestiones cuanto diferir indefinidamente las trabajosas tareas de deslinde y esclarecimiento conceptual.

Pero el asistematismo, por supuesto que relativo, de Zea, no nos impide a nosotros tentar aproximaciones sistemáticas a sus desarrollos. Tampoco nos impide retomar determinados aspectos de los mismos con fines más sistemáticos. Más arriba escribí que la ecuación Zea no tematiza un rechazo en bloque a la civilización moderna ni un retorno al pasado tradicional ni, todavía menos, a la barbarie, sino que propone, más bien, la preservación y promoción de incrustaciones Gemeinschaft en el seno de la sociedad moderna. Enseguida agregué, buscando una caracterización más ajustada, que la ecuación tematiza el anhelo de que el mundo todo cambie a partir de la interpelación de los ámbitos Gemeinschaft. La lectura de Toynbee por Zea, así como también la rectificación de Hegel que emprendió con base en ella, prevé ciertamente un lieto fine global, signado por el predominio de un universalismo auténtico, respetuoso de las particularidades. Todo esto significa que la ecuación Zea postula que el espíritu de comunidad es algo así como la palanca arquimédica con base en la cual resultaría posible pensar la transformación universal. No debemos olvidar el sentido original de toda la búsqueda: desde los años cuarenta que el fervor de lo propio estaba articulado a la promesa de una metafísica conectada a la superación de la crisis del mundo. Fervor y promesa son, sin duda, las dos caras de la misma moneda, y se condensan y potencian en la idea-imagen del espíritu de comunidad. Labrada con grandes esfuerzos, esta idea-imagen es, en Zea, la llave para acceder al lieto fine. Todo sucede como si en el espíritu de comunidad resonase algo que, al trascender lo inmanentista/utilitario/despersonalizador, permite que el regateo de humanidad sea desplazado por el ánimo de incorporación. No necesariamente por el ánimo de incorporación que orientó el mestizaje durante la época colonial, el cual también, al utilizar a los naturales americanos como animales domésticos, practicó una forma específica de regateo. Zea insiste muchas veces en que lo verdaderamente importante es la forma de convivencia que se anhela alcanzar. En destacar todo esto consiste el trabajo de diamantado del espíritu de comunidad, esa idea-imagen compuesta, como ahora sabemos, de elementos múltiples y dispares, de diamantes y herrumbre.

En la ecuación Zea es posible, y además deseable, aspirar al más alto nivel de desarrollo permaneciendo fieles a lo propio, al espíritu de comunidad. El pathos implicado no se contrapone a una sensibilidad productivista o (neo)desarrollista. Lo propio no es visto como obstáculo. No es algo arcaico que se deba sepultar. Es algo vivo y, además, apreciable. Ávida de acceder a lo mejor de la modernidad y deseosa de gozar de los frutos del desarrollo, la ecuación Zea no deja lugar para una reacción del estilo de la de la zorra esópica. Tampoco deja lugar para que los diamantes tan trabajosamente encontrados funcionen apenas como bálsamo retórico, como discreto refugio o como simple amortiguador de las facetas menos apreciables de la modernidad. Palanca arquimédica, el espíritu de comunidad es también, en la imaginaria reescritura zeiana de la fábula esópica, lo que puede redimir a todos los participantes del drama. Esto es pensable dada la supuesta capacidad de ese espíritu de hacer que los frutos se vuelvan accesibles para todos y que, justamente por eso, resulten más deliciosos. 


\section{BIBLIOGRAFIA}

ÁLVARO, Daniel. Los conceptos de "comunidad" y "sociedad" de Ferdinand Tönnies. Papeles del CEIC, Universidad del País Vasco, v. 01, n. 52, 2010.

ARÉVALO, Juan José. Fábula del tiburón y las sardinas: América Latina Estrangulada. México: América Nueva, 1956.

BATAILLON, Marcel. Erasmo y España. Estudios sobre la historia espiritual del siglo XVI. México: Fondo de Cultura Económica, 1950.

BAUMAN, Zygmunt. Comunidad. En busca de seguridad en un mundo hostil. Buenos Aires: Siglo Veintiuno, 2003.

BOLTANSKI, Luc; CHIAPELLO, Éve. El nuevo espíritu del capitalismo. Madrid: Akal, 2010.

CASTRO, Américo. España en su historia: cristianos, moros y judíos. Buenos Aires: Losada, 1948.

DE MARINIS, Pablo. 16 comentarios sobre la(s) sociología(s) y la(s) comunidad(es). Papeles del CEIC, Universidad del País Vasco, v. 01, n. 52, 2010.

DE MARINIS, Pablo (coord.). Comunidad: estudios de teoría sociológica. Buenos Aires: Prometeo, 2012. ECHEVERRÍA, Bolívar. La modernidad de lo barroco. México: Era, 2000.

GAOS, José. Obras Completas. Tomos V, VI y IX. México: UNAM, 1993, 1990 y 1992, respectivamente. GAOS, José. Carta abierta a Leopoldo Zea. Cuadernos Americanos, México, enero-febrero de 1950. GAOS, José. España en su historia. Cuadernos Americanos, México, n. 05, 1949.

GAOS, Vicente. Una interpretación de España. España en su historia, de Américo Castro. Filosofía y Letras, México, n. 37, 1950.

KOZEL, Andrés. La idea de América en el historicismo mexicano. José Gaos, Edmundo O'Gorman, Leopoldo Zea. México: El Colegio de México, 2012.

MORSE, Richard. El espejo de Próspero. Un estudio de la dialéctica del Nuevo Mundo. México: Siglo Veintiuno, 1982.

O'GORMAN, Edmundo. ¿Tienen las Américas una historia común?, Filosofía y Letras, México, n. 06, 1942.

O'GORMAN, Edmundo. Sobre la naturaleza bestial del indio americano. Filosofía y Letras, México, México, n. 01, 1941.

SCHLUCHTER, Wolfgang. Ferdinand Tönnies: comunidad y sociedad. Signos Filosóficos, México, v. 13, n. 26, 2011.

SVAMPA, Maristella y VIALE, Enrique. Maldesarrollo. La Argentina del extractivismo y el despojo. Buenos Aires: Katz, SD.

TOYNBEE, Arnold. México y el Occidente. México: Antigua Librería Robredo, 1955.

TOYNBEE, Arnold. El mundo y el Occidente. Madrid: Aguilar, 1953.

ZEA, Leopoldo. José Gaos: el transterrado. México: UNAM, 2004.

ZEA, Leopoldo. Conciencia y posibilidad del mexicano. El Occidente y la conciencia de México. Dos ensayos sobre México y lo mexicano. México: Porrúa, 2001.

ZEA, Leopoldo. Formas de convivencia en América, en La esencia de lo americano. Buenos Aires: Pleamar, 1971.

ZEA, Leopoldo. Dos formas de vida en América. En: Diánoia, México, n. 09, 1963.

ZEA, Leopoldo. América en la historia. México: Fondo de Cultura Económica, 1957. 
ZEA, Leopoldo. Alemania en la cultura hispanoamericana. En: Esquema para una historia de las ideas en Iberoamérica, México, UNAM, 1956

ZEA, Leopoldo. ¿Bondad norteamericana e ingratitud mundial? En: Cuadernos Americanos, México, enero-febrero de 1955.

ZEA, Leopoldo. América como conciencia. México: Cuadernos Americanos, 1953.

ZEA, Leopoldo. Dos etapas del pensamiento en Hispanoamérica. Del romanticismo al positivismo. México: El Colegio de México, 1949.

ZEA, Leopoldo. Norteamérica en la conciencia hispanoamericana. Cuadernos Americanos, México, 1948.

ZEA, Leopoldo. En torno a una filosofía americana. México: El Colegio de México, 1945. 